\title{
Den characteristics and ecological significance of Marmota himalayana on the Qinghai-Tibet Plateau
}

\author{
Shulin Wang ${ }^{1}$ and Fujiang Hou ${ }^{1}$ \\ ${ }^{1}$ Affiliation not available
}

January 14, 2021

\begin{abstract}
Dens are places for cavernicolous animals to hibernate, reproduce, and avoid predators and harsh weather conditions, and thus they have a vital impact on their survival. M. himalayana is the main large cavernicolous rodent on the Qinghai-Tibet Plateau. The analysis of den traits and their ecological functions can reveal mechanisms by which marmots have adapted to their environment, which is important for further understanding the ecological significance of this species. From July to August 2019 (warm season), we used unmanned aerial vehicles to fly at low altitudes and slow speeds to locate 131 marmot burrows (45 on shaded slopes, 51 on sunny slopes, and 35 on flat areas) in the northeastern Qinghai-Tibet Plateau. We then measured the physical characteristics (den density, entrance size, first tunnel length, volume, orientation and plant characteristics near the den entrance) of these dens on site. The physical parameters of the M. himalayana dens showed that they function to protect the marmots from natural enemies and bad weather, provide good drainage, and maintain a stable microclimate around the entrance. This is a result of the marmot's adaptation to the harsh environment (cold and humidity) of the Qinghai-Tibet Plateau.
\end{abstract}

\section{INTRODUCTION}

Dens used by cavernicolous animals have a vital impact on their survival. Dens provide animals with a place to rest, hide, and hibernate and help them avoid bad weather and predators (Ross et al. 2010; Tsunoda et al. 2018). The ecological characteristics of a den can accurately reflect the life, behavior, and social networks of cavernicolous animals. For example, the yellow-bellied marmot (Marmota flaviventris) in North America uses dens that resist harsh environments and predators during hibernation and provide a protective shelter in summer (Svendsen 1976). Pallas's cat (Otocolobus manul), which inhabits the Mongolian plateau, cannot dig burrows by itself, so it often uses Marmota sibiricadens to give birth, raise offspring, and avoid natural enemies; the availability of $M$. sibirica dens thus has a very important impact on the stability of the $O$. manul population (Ross et al. 2010). The puma (Puma concolor) living in the American continent uses dens to defend against predators (e.g., adult Ursus arctos ) and to maintain microclimate stability, therefore increasing the survival rate of its cubs (Bleich et al. 1996; Benson et al. 2008). American black bears (Ursus americanus ) use various types of dens (excavated, trees, rock cavities) for hibernation, and their dens provide safe places for female black bears to give birth and rear their cubs; in addition, some individuals use tree dens that can resist flooding (White et al. 2001). Therefore, dens offer an excellent means of studying the ecological adaptation of cavernicolous animals.

Except for plateau rabbits (Lepus oiostolus ), Marmota himalayana (hereafter referred to as the marmot) is the only large rodent in the alpine meadows of the Qinghai-Tibet Plateau (QTP). Marmots are herbivores and forage mainly on the leaves and stems of Cyperaceae, Gramineae, and the flowers of legume species. Marmots are of great significance to the stability of the alpine meadow ecosystem. First, the marmot is an important part of the food chain in the grassland ecosystem. It is important prey for large raptors, foxes, and wolves. In addition, marmots feed on grasslands that cannot be reached by livestock, which is 
equivalent to grazing in these areas and is good for the health of the grasslands (Oesterheld and McNaughton 1991). The burrowing and digging behavior of marmots is conducive to the circulation of organic matter in the grasslands. However, marmots do also cause obvious harm, as they compete with livestock for fine pasture, dig grass roots, and destroy turf all year round. In the pasture, marmot holes are the main hidden danger that causes livestock leg fractures (Chen 1982). Each of their excavated mounds covers a large area of grassland $\left(\sim 2 \mathrm{~m}^{2}\right)$, causing ground collapse, soil erosion, and desertification. Marmots are also one of the main spreaders of the plague in this region (Xu et al. 2020), which seriously threatens the health of grassland herders and livestock.

Habitat selection is a reflection of the environmental, ecological, and physiological requirements of a species (Kohji and Kenichi 1998). When cavernicolous animals excavate dens, they typically show a strong selectivity with respect to the surrounding environment. For example, the Japanese red fox (Vulpes vulpes ) prefers to dig dens closer to a water source (Kohji and Kenichi 1998). On the north coast of Alaska, the arctic fox (Alopex lagopus ) prefers to choose dens on the southern slope in an area with thin permafrost (Garrott et al. 1983), which helps to keep the den warm.

In this study, marmot dens that were present in different terrains (sunny slopes, shady slopes, and flat areas) were located, and the physical characteristics of these dens were measured under harsh environmental conditions (low oxygen, low temperature, and high precipitation) (Zhang et al. 2019). Here we determined (1) the general physical characteristics and ecological functions of marmot dens and (2) whether there are differences in den traits under different terrains. Our findings highlight the adaptation mechanism of $M$. himalayanawith respect to its environment, which is of great significance for further understanding the ecological characteristics of the marmot or other cavernicolous animals all over the world.

\section{MATERIAL AND METHODS}

\section{Study area}

The present study was undertaken at the Lanzhou University Research Station in Maqu County, Gansu Province, China (101 $53^{\prime} \mathrm{E}, 33 \mathrm{deg} 58^{\prime} \mathrm{N}, 3500 \mathrm{~m}$ a.s.l.). This area is located in the northeast of the QTP. The climate is cold and humid, with only a warm season (May to September) and cold season (October to April) (Sun et al. 2015). There is no absolute frost-free period throughout the year. The annual average temperature is about $1.2 \mathrm{degC}$, and the highest temperatures are from June to August, with an average of $<12 \operatorname{deg} C$; the lowest temperatures (average of $-10 \operatorname{deg} C$ ) are from December to February. The average annual rainfall is $\sim 620 \mathrm{~mm}$, which occurs mainly during the forage growing season (May to September). These soils are classified as Mat-Cryic Cambisols based on previous experimental work (Sun et al. 2015), and the vegetation is characteristic of a typical alpine meadow (Yang et al. 2019). Cyperaceae (Kobresia graminifolia , Kobresia humilis, and Kobresia pygmaea) constitute the constructive species, and Gramineae (Elymus nutans and Poa pratensis ), Compositae (Saussurea hieracioides, Aster diplostephioides, and Anaphalis lacteal), Ranunculaceae (Saussurea hieracioides, Anaphalis lacteal, Anemone rivularis, Anemone trullifolia , and Anemone obtusiloba), and other associated plants are widely distributed among them, in addition to scattered Potentilla fruticosa shrubs (Yang et al. 2019). The entire study area has undulating mountains, with steep and changeable, complex, and fragmented terrain.

\section{Research object}

Marmots are hibernation animals. When the temperature is consistently $<10$ degC, they will hibernate naturally for 3-6 months and will then wake up naturally when the temperature warms. Marmots are family den social animals. Dens are generally classified as hibernation dens, summer-living dens, and temporary dens according to their functions. Each family has a den group. The den group is centered on a hibernation den and is surrounded by several summer lived dens and temporary dens.

The natural enemies of marmots in this study area are mainly stray dogs (Canis lupus familiaris), Tibetan foxes (Vulpes ferrilata), and large raptors (Bubo bubo and Buteo hemilasius ). Marmots are very cautious and often look up to observe the surrounding environment during foraging. Their area of activity is typically 
concentrated within 2-100 $\mathrm{m}$ of their den entrance (Yang and Xie 1983). When they are disturbed by humans or other predators, they will sound an alarm, and the surrounding individuals will immediately enter the den after hearing the alarm (Shi 2007; S.L. Wang, personal observation, 2019). Marmots in this region begin to hibernate during mid-October and are almost all hibernating by the end of October; they end their hibernation at the end of March or in early April (Shi 2007). During the entire warm season, except for periods with severe weather (e.g., heavy rain and/or hail), they are active outside their dens. Generally, they leave their dens at sunrise and return at sunset.

\section{Den location and field measurement}

The entrance of a marmot den is oval in shape, with excavated soil/gravel piled up near the entrance (Fig. 1), which results in a truncated cone-shaped pile that is obviously different from the surrounding grassland (Appendix Fig. A1). In addition, marmots often traverse a fixed route around the den entrance, trampling on the grass and forming a path that is easy identified (Appendix Fig. A2). Tibetan foxes occasionally are seen in the study area, and they may use dens that have been abandoned by marmots. However, it is easy to distinguish between the den entrance of a fox and a marmot (Appendix Fig. A1).

Marmot dens were investigated during the summer (July to September) of 2019 by searching the study area from unmanned aerial vehicles (UAVs) flying 40-50 m above the ground at speeds of $30-50 \mathrm{~km} / \mathrm{h}$. Dens located during aerial surveys were ground checked to verify their identity based on the presence of a large amount of marmot scat (Appendix Fig. A3), footprints, trails, and the presence of an adult or cubs (Garrott et al. 1983).

During the entire study period, we investigated 32 sites and 131 dens (51 on sunny slopes (facing south or west), 45 on shady slopes (facing north or east), and 35 in flat areas). We did not carefully distinguish between temporary dens, summer lived dens, and hibernation dens. We measured the following indicators of these dens and the surrounding environment.

(1) Den density: We calculated the den density for each terrain based on the area of the surveyed sites as scanned by UAVs (Qin et al. 2019) and the number of dens recorded.

(2) Den entrance size: As the den entrance of M. himalayana is oval in shape, it thus has two parameters, the long axis $(a)$ and the short axis $(b)$. The entrance area $(\mathrm{S})$ was calculated using the following formula:

$\mathrm{S}=\pi \times \frac{a}{2} \times \frac{b}{2}(1)$

(3) First tunnel length: We used a measuring tape to measure the length from the entrance to the first corner of the tunnel.

(4) Den volume: We used the equal volume method to measure the tunnel volume based on the pile of dirt beside each den. The volume of the truncated cone-shaped pile is approximately equal to the tunnel volume:

$\mathrm{V} \approx \frac{1}{3} \times \mathrm{H} \times \pi \times\left(\mathrm{R}^{2}+\mathrm{R} \times \mathrm{r}+\mathrm{r}^{2}\right)(2)$

Where $\mathrm{V}$ is the tunnel volume; $\mathrm{H}$ is the height of the mound; and $\mathrm{R}$ and $\mathrm{r}$ represent the upper and lower radius of the mound, respectively.

(5) Den orientation and angle of den entrance: We used a rangefinder (Aicevoos Z5, China) to measure the orientation and angle of the entrance. Here we divided the den orientation into eight directions: $\mathrm{N}$ (0deg, at the top (12 o'clock) position), NE (1deg-89deg), E (90deg), SE (91deg-179deg), S (180deg), SW (181deg-269deg), W (270deg), and NW (271deg-360deg).

(6) Path density near the den entrance: We determined the path density according to the trampling situation of the vegetation around the den entrance.

(7) Vegetation characteristics near the den entrance: For each den, to avoid any influence of the mound, we selected a quadrat $(0.5 \mathrm{~m} \mathrm{x} 0.5 \mathrm{~m})$ in the opposite direction of the mound and $30 \mathrm{~cm}$ away from the den entrance (referred to as the near entrance quadrat). At the same time, we analyzed a control quadrat (CK) 
at a distance of $30 \mathrm{~m}$ (referred to as activity area) away from the den entrance. Individual plant species (referring to species richness) and the height of each species (referring to an average height per species) were recorded in each quadrat, and aboveground vegetation was collected and dried to a constant weight at 65 $\operatorname{deg} \mathrm{C}$.

\section{Statistical analyses}

Data were analyzed using Statistical Package for the Social Sciences (SPSS) (version 26.0; SPSS, Inc., Chicago, IL, USA). Data were checked for normal distribution using the Shapiro-Wilk test. Data for marmot den characteristics that were not indicated as being normally distributed were $\log _{10}$-transformed to pursue normality and homogeneity of variances. We set terrains as fixed effects and replicates as a random effect. Factorial ANOVA (One-way ANOVA) analysis of variance with a least significant difference (LSD) test for multiple comparisons was used to compare various indicators of marmot den characteristics among different terrains. Figures were constructed using Origin 9.1.

Principal component analysis (PCA) was performed to study the relationship between the environmental variables (terrain and plant traits) and the den characteristics. PCA was performed using CANOCO version 5.0 (Šmilauer and Lepš 2014).

\section{RESULTS}

\section{Den density}

According to the area searched by UAVs, the den density on shady slopes, on sunny slopes, and in flat areas was $0.83,0.97$, and $0.60 /$ ha, respectively. The den density on sunny slopes was significantly higher than that on shady slopes and in flat areas $\left(\mathrm{F}_{2}, 128=3.47, P<0.05\right)$ (Fig. 2), which means that marmots prefer to dig burrows on sunny slopes.

\section{Den entrance size}

The long axis $(28.59 \pm 4.32 \mathrm{~cm})$ of the oval-shaped entrances was significantly longer than the short axis $(22.95 \pm 3.57 \mathrm{~cm})\left(\mathrm{F}_{1,129}=3.24, P<0.05\right)$. The average length of the long axis among entrances in flat areas $(31.00 \pm 4.27 \mathrm{~cm})$ was significantly longer than that on sloped terrain $(27.21 \pm 3.71 \mathrm{~cm})\left(\mathrm{F}_{1,129}=\right.$ $3.37, P<0.05)$. There was no significant difference in the length of the short axis of the entrance among different terrains $\left(\mathrm{F}_{2,128}=4.32, P=0.082\right)$. In addition, there was no significant difference in the entrance area among the shady slopes $\left(0.19 \pm 0.03 \mathrm{~m}^{2}\right)$, the sunny slopes $\left(0.19 \pm 0.04 \mathrm{~m}^{2}\right)$, and the flat areas $(0.22$ $\left.\pm 0.06 \mathrm{~m}^{2}\right)\left(\mathrm{F}_{2,128}=2.34, P=0.073\right)$ (Fig. 3).

\section{First tunnel length}

Across all dens, the average length of the first tunnel was $248.64 \pm 23.67 \mathrm{~cm}$. The first tunnel length of the dens on the shady slopes and sunny slopes and in flat areas was $257.50 \pm 101.33,226.67 \pm 93.93$, and 256.25 $\pm 76.15 \mathrm{~cm}$, respectively, and the differences among them were significant $\left(\mathrm{F}_{2,128}=4.37, P<0.05\right)$ (Fig. 4).

\section{Tunnel volume}

Tunnel volume was not significantly different among dens on shady slopes $(0.26 \pm 0.08)$ and sunny slopes $(0.32 \pm 0.15)$ and in flat areas $(0.29 \pm 0.17)\left(\mathrm{F}_{2,128}=3.25, P=0.077\right)$ (Fig. 5).

\section{Den orientation}

Among the 45 dens on shady slopes, $37.50 \%$ had an east-facing exposure, $25.00 \%$ had a northeast-facing aspect, and $37.50 \%$ were oriented to the southeast. Among the 51 dens on sunny slopes, $20.00 \%$ had southfacing exposures, $30.00 \%$ had a southwest-facing aspect, and $50 \%$ were oriented to the west. Among the 35 dens in flat areas, $37.50 \%$ had east-facing exposures, $25.00 \%$ had a south-facing aspect, and $37.50 \%$ were oriented to the southwest (Fig. 6).

\section{Angle of den entrance}


Based on our on-site measurements, we found that the angle of the den entrance on shady slopes was 32.87 $\pm 3.98^{\circ}$, which was significantly lower than that on sunny slopes $\left(38.67 \pm 4.23^{\circ}\right)$ and in flat areas $(38.13$ $\left.\pm 3.92^{\circ}\right)\left(\mathrm{F}_{2,128}=1.39, P<0.05\right)$. However, the angle of the den entrance was not significantly different between those on sunny slopes and in flat areas $\left(\mathrm{F}_{1,129}=2.37, P=0.083\right)$ (Fig. 7).

\section{Path density around the den entrance}

Path density around the den entrance reflects the activity intensity of $M$. himalayana. There was an average of $2.68 \pm 0.82$ paths per den. The path density for dens on shady slopes and sunny slopes and in flat areas was $2.75 \pm 0.97,2.33 \pm 0.75$, and $2.88 \pm 0.59$, respectively; there were no significant differences in path densities $\left(\mathrm{F}_{2,128}=3.28, P=0.065\right)$ (Fig. 8).

\section{Plant characteristics near the den entrance and active area}

Species richness near the den entrance (16.76 \pm 3.59 species) was significantly lower than that in the active area $(31.92 \pm 3.43$ species $)$ across all dens $\left(\mathrm{F}_{1,129}=2.73, P<0.05\right)$. Species richness in active areas near dens in flat areas was significantly higher than that on sloping terrain $\left(\mathrm{F}_{1,129}=0.85, P<0.05\right)$. There was no significant difference in species richness near the entrance of the dens among the three terrains $\left(\mathrm{F}_{2}, 128\right.$ $=4.41, P=0.061)($ Fig. 9).

Species height in the quadrat near the den entrance $(20.28 \pm 4.19 \mathrm{~cm})$ was significantly lower than that in the active area quadrat $(28.30 \pm 3.52 \mathrm{~cm})\left(\mathrm{F}_{1,129}=2.92, P<0.05\right)$. Species height near the entrance on shady slopes $(26.96 \pm 4.67 \mathrm{~cm})$ was significantly higher than that near the entrance on sunny slopes (11.00 $\pm 2.12 \mathrm{~cm})$ and in flat areas $(19.71 \pm 3.74 \mathrm{~cm})\left(\mathrm{F}_{2,129}=3.83, P<0.05\right)$ (Fig. 9).

Across all dens, aboveground biomass in the activity area $(222.72 \pm 39.51 \mathrm{~g})$ was significantly higher than that near the den entrance $(150.77 \pm 30.62 \mathrm{~g})\left(\mathrm{F}_{1,129}=2.78, P<0.05\right)$. The aboveground biomass near the den entrance on sunny slopes $(113.03 \pm 24.17 \mathrm{~g})$ was significantly lower than that on shady slopes (162.81 $\pm 17.96 \mathrm{~g})$ and in flat areas $(166.91 \pm 16.70 \mathrm{~g})\left(\mathrm{F}_{2,129}=3.23, P<0.05\right)($ Fig. 9).

\section{Relationship between environmental factors and den characteristics}

In a PCA of these data, principal component (PC) 1 and PC 2 explained $89.11 \%$ of the total variation in the environmental characteristics (axis $1=76.73 \%$, axis $2=12.38 \%$ ). Terrain had a substantial influence on den density, orientation, and entrance size and on the angle of the den entrance. In addition, species richness had a substantial impact on path density and tunnel volume (Fig. 10).

\section{DISCUSSION}

\section{Den site selection by marmots}

The underground structure of marmot dens is very complex, and digging a complete burrow requires a lot of work. Animals tend to use the smallest investment of energy to get the greatest return (Mcfarland 1993). Marmots decide where to dig their dens only after careful consideration, and, therefore, environmental factors (i.e., the terrain and plant traits) have an important influence on their site selection behavior.

We found that den density on shady and sunny slopes was higher than that in flat areas (Fig. 2; Fig. 10). Topographic characteristics directly affect the moisture and thickness of the soil. Dens located on slopes may allow a more extensive system of burrows to be excavated (Garrott et al. 1983). A den must be dry and have clean underground shelters in which marmots can live (Shi 2007). Although flat areas are conducive to digging burrows, alpine meadow have frequent precipitation during the warm season and rainwater can easy flow into the den. Therefore, the den density is lower in flat areas. The soil layer on the shady slopes in this region is thick $(\sim 1 \mathrm{~m})$ relative to that on the other two regions (He and $\mathrm{Li} 2016)$ and is therefore convenient for marmots to build their underground den systems. In areas where the soil is shallow and the lower layer is rocky, it is difficult for marmots to excavate burrows. A study that looked at den site preference indicated that Arctic foxes like to dig dens on slopes with thin permafrost $(30 \mathrm{~cm})$ (Garrott et al. 1983). Marmots like to excavate their burrows on sunny slopes, in addition to their need for a dry and comfortable habitat, they 
also benefit from basking in the sun and staying warm, which is vital for avoiding cold temperatures and to avoid freezing in winter after they hibernate (Shi 2007).

\section{Den characteristics and functions}

The shape of the den entrance is typically determined by the morphological structure of the inhabitant. Marmots have a flattened body shape. This body shape is conducive to remaining close to the ground to avoid being discovered by predators when the marmots are active outside the den. Field measurements were used to determine that the long axis of the oval-shape entrance to these dens was significantly longer than the short axis (Fig. 3). These dimensions are larger than the den entrance diameter $(27$ and $19 \mathrm{~cm}$ for the long and short axis, respectively) of the steppe marmot (Marmota bobak Müll.) that inhabits the Ukraine (Nikol'Skii and Savchenko 2002). The shape and size of the den entrance facilitate the rapid entry of the marmot while preventing predators from entering (Rodrick and Mathews 1999). There was no significant difference in the area of the den entrance among different terrains, which suggests that the size of the den entrance helps to maintain a stable temperature inside the den (Nikol'Skii and Savchenko 2002), which is an adaptive strategy used by marmots to protect themselves and to reduce the possible impact of the external environment (Jia et al. 1991). We also found that dens in flat areas had a longer long axis relative to the long axis of dens on slopes. This may be due to the wider field of vision that marmots have access to on slopes; thus, a larger den entrance makes it easier for a marmot hiding inside the den to observe potential predators.

We found that the average first tunnel length was $248.64 \mathrm{~cm}$ (Fig. 4), which is longer than that $(127.3 \mathrm{~cm})$ of dens in other parts of the QTP (Zhang et al. 2019); this difference is most likely due to the different geographical and climatic conditions across different regions. The first tunnel is deep and long, which can increase the infiltration distance of rainwater after entering the tunnel, thereby minimizing the accumulation of water deeper within the den. This is especially important in rainy areas (i.e., the QTP). In addition, the shortest length of the first tunnel in this study was $100 \mathrm{~cm}$, which is greater than the average body length of $M$. himalayana $(55 \mathrm{~cm}$ ) and thus ensures that they can enter the den quickly to avoid predators (Zhang et al. 2019).

Tunnel volume reflects the internal structural traits of the marmot den. We found that on average the den volume was $0.29 \mathrm{~m}^{3}$, slightly larger than that $\left(0.23 \mathrm{~m}^{3}\right)$ in other parts of the QTP (Wang 1992), but there was no significant difference in the den volume among the different terrains analyzed here (Fig. 5). The underground den system has a complex internal structure and multiple nests, which are places for marmots to breed, hibernate, and store food (hay). The truncated cone-shape mound near the den entrance represents an observatory for the resident marmot(s). They often stand on the mound to observe the environment around the den entrance (sometimes for $>1 \mathrm{~h}$ ), and they become active around the entrance only after confirming that there is no potential danger (Yang and Xie 1983). These mounds do, however, form a large number of naked spots on the grassland and represent one of the main reasons for grassland degradation in this region (Chen 1982).

Whereas the aspect of a den may confer certain advantages, the direction of the den opening may be related to site-specific conditions such as vegetation, drainage, or climate (Rodrick and Mathews 1999). Among the 131 dens surveyed in this study, there were no dens oriented toward the north, and only a few $(9.09 \%)$ dens located on shady slopes displayed a northeast aspect (Fig. 6). Danilov (1961) suggested that dens oriented southward have a more favorable microclimate because of the protection from the prevailing northeasterly winds. For example, den orientation for the red fox on Assateague Island, Maryland, is often associated with local prevailing wind directions (Krim et al. 1990). Chesemore (1969) found that most entrances of arctic fox dens had a southerly, easterly, or westerly orientation, possibly indicating a preference for a warmer exposure. We did not, however, assess any microclimatic variables of the dens in this study.

The angle between the tunnel and the ground has an important influence on the structural stability of the den. We found that on average the angle of the den entrance was $36 \pm 4.82^{\circ}$ (Fig. 7), which is smaller than that of a previous study $\left(45^{\circ}\right)$ (Zhang et al. 2019). A smaller angle of the den entrance results in structural 
instability, and makes it easy for the den to collapse, especially in pastures, where this hidden danger leads to leg fractures among large livestock. In contrast, a larger angle makes it difficult to dig the burrow and the excavated soil can easily backfill the tunnel; in addition, rainwater easily collects in the den. Thus, the moderate angle noted here is the result of a trade-off between structural stability and better drainage (Wang and Wang 2006).

Marmots are timid by nature. When they are active outside their dens, they walk along a fixed route, trampling the grass and forming a path. The number of paths reflects the activity intensity of a marmot near its den entrance. We found that these paths are arranged radially around the entrance, with an average of $2.68 \pm 0.82$ paths near each entrance (Fig. 8). Marmots are one of the main spreaders of bubonic plague in this region (Xu et al. 2020), and thus one method to control the spread of this disease is the use of annular mousetraps to trap and kill marmots. If mousetraps are laid out on the path near the den entrance, the capture rate can be increased (Zhou et al. 2019).

\section{Plant characteristics near the den entrance}

Vegetation characteristics (richness, height, and biomass) have an important influence on the den-selecting behavior of marmots (Li et al. 2017). We found that species richness in marmot activity areas was significantly higher than that near the den entrance (Fig. 9). The active area for these marmots was mainly concentrated within 2-100 $\mathrm{m}$ near the den entrance. Plants in the active area provide food and water for the marmots, as well as bedding for their nests in winter. Marmots like to feed on succulent and highly nutritious forage and can get enough water from their forage without additional water. Generally, marmots like to excavate burrows on sloped terrain, but we found that there were also some dens in flat areas $(0.60 / \mathrm{ha})$, and the species richness in those areas was significantly higher than that on sloped terrain. High species richness may be the reason why marmots are attracted to these places to dig dens (Shi 2007).

Plant height also has a significant influence on the activities of marmots (Li et al. 2017). We found that plant height within the activity area was significantly higher than that near the den entrance (Fig. 9). The low plants near the den entrance allow marmots to hide in their tunnels while observing the outside environment (Shi 2007), thus ensuring that there is no danger before they leave their dens. In addition, marmots often stand and observe their surroundings when feeding, and the exposed den entrance serves as a marker, which helps them return to their den quickly when danger is detected (Zhang et al. 2019).

Because marmots are active only near the entrance to their dens, the availability of food in those areas directly affects their den-selecting behavior and quality of life. We found that the aboveground biomass in the active area was significantly higher than that near the den entrance (Fig. 9). Abundant food sources ensure that marmots can reserve enough energy before hibernation to prepare for the 6-month hibernation period (October to April).

\section{CONCLUSIONS}

Den characteristics of $M$. himalayana are the result of adaptation to the harsh environment of the QTP. Their physical parameters indicate that dens function in the avoidance of natural enemies and bad weather, in providing good drainage, and in maintaining a stabile microclimate. In addition, this study also provides a theoretical basis for the mechanism by which $M$. himalayana adapted to its environment.

\section{ACKNOWLEDGMENTS}

The authors wish to thank Gericaidan (head of Maqu research station) for field assistance.

\section{CONFLICT OF INTEREST}

None.

\section{AUTHOR CONTRIBUTIONS}

Shulin Wang collected and analyzed the data and wrote the paper. Fujiang Hou designed the research and assisted with paper revision. 


\section{DATA ACCESSIBILITY}

Data are available through the Figshare (https://doi.org/10.6084/m9.figshare.13365329)

\section{ORCID}

Shu-lin Wang https://orcid.org/0000-0003-0776-8912

Fu-jiang Hou https://orcid.org/0000-0002-5368-7147

\section{REFERENCES}

Benson, J.F., Lotz, M.A., and Jansen, D. 2008. Natal den selection by Florida panthers. Journal of Wildlife Management. 72(2): 405-410. doi:10.2193/2007-264.

Bleich, V.C., Pierce, B.M., Davis, J.L., and Davis, V.L. 1996. Thermal characteristics of mountain lion dens. Great Basin Naturalist. 56(3): 276-278. doi:10.2307/41712946.

Chesemore, D.L. 1969. Den ecology of the Arctic fox in northern Alaska. Canadian Journal of Zoology. 47(1): 121-129. doi:10.1139/z69-021.

Chen, J. 1982. The effect of Marmota Himalayana Hodgson on the vegetation of Xiahe grassland region. Journal of Lanzhou University (natural sciences). 18(2): 148-152. doi: CNKI:SUN:LDZK.0.1982-02-015.

Danilov, D.N. 1961. Den sites of the arctic fox (Alopex lagopus ) in the east part of the Bolshezemelskaya tundra. Problems of the North. No. 2 (Translation). National Research Council of Canada, Ottawa. pp. 225-229.

Garrott, R.A., Eberhardt, L.E., and Hanson, W.C. 1983. Arctic fox den identification and characteristics in northern Alaska. Canadian Journal of Zoology. 61(2): 423-426. doi: 10.1139/z83-056.

He, J.L, and Li, X.G. 2016. Potentilla fruticosa has a greater capacity to translocate phosphorus from the lower to upper soils than herbaceous grasses in an alpine meadow. Agriculture Ecosystems and Environment. 228: 19-29. doi: 10.1016/j.agee.2016.04.021.

Jia, J.B., Xiao, Q.Z., Xu, L., and Ma, H.S. 1991. A primary observation of the Red fox dens. Acta Theriologica Sinica. 11(4): 266-269. doi: CNKI:SUN:SLXX.0.1991-04-004.

Kohji, U., and Kenichi, T. 1998. Den site selection and utilization by the red fox in Hokkaido, Japan. Mammal Study. 23(1): 31-40. doi: 10.3106/mammalstudy.23.31.

Krim, P.M., Bashore, T.L., and Kirkland, G.L. 1990. Den site characteristics and food habits of the red fox (Vulpes vulpes ) on Assateague Island, Maryland. Virginia Journal of Science. 41: 340-351.

Li, H.Y., Chen, H.j., Li, X., Mi, B.Y., Zhou, K.Z., Li, Q., Ouer Geli,Zhang, A.P. and Wang, Z.Y. 2017. A preliminary study on Himalaya marmot habitat vegetation condition in Qinghai Province. Chinese Journal of Endemiology. 36(6): 400-404. doi: 10.3760/cma.j.issn.2095-4255.2017.06.003.

Mcfarland, D. 1993. Animal behaviour: psychobiology, ethology and evolution. The Quarterly Review of Biology. 61(2): 289-290.

Nikol'Skii, A.A., and Savchenko, G.A. 2002. Air temperature changes in a steppe marmot burrow in the summer-autumn period. Russian Journal of Ecology. 33(2): 109-114. doi: 10.1023/A:1014452808571.

Oesterheld, M., and McNaughton, S.J. 1991. Effect of stress and time for recovery on the amount of compensatory growth after grazing. Oecologia. 85(3): 305-313. doi: 10.1007/BF00320604.

Qin, Y., Yi, S.H., Ding, Y.J., Qin, Y., Zhang, W., Sun, Y., Hou, X.M., Yu, H.Y., Meng, B.P., Zhang, H.F., Chen, J.J., and Wang, Z.W. 2020. Effects of plateau pikas' foraging and burrowing activities on vegetation biomass and soil organic carbon of alpine grasslands. Plant and Soil. 4: 1-16. doi: 10.1007/s11104-02004489-1. 
Rodrick, P.J. and Mathews, N.E. 1999. Characteristics of natal and non-natal kit fox dens in the northern Chihuahuan Desert. Great Basin Naturalist. 59(3): 253-258. doi: scholarsarchive.byu.edu/gbn/vol59/iss3/6.

Ross, S., Kamnitzer, R., Munkhtsog, B., and Harris, S. 2010. Den-site selection is critical for Pallas's cats (Otocolobus manul). Canadian Journal of Zoology. 88(9): 905-913. doi: 10.1139/Z10-056.

Shi, S.M. 2007. Habitat selection by Marmota himalayana . Thesis, College of Life Science and Technology, Gansu Agricultural University, Lanzhou, China.

Šmilauer, P., and Lepš, J. 2014. Multivariate Analysis of Ecological Data using CANOCO 5. 2nd ed. Cambridge: Cambridge University Press.

Svendsen, G. 1976. Structure and location of burrows of yellow-bellied marmot. The Southwestern Naturalist. 20: 487-494.

Sun, Y., Angerer, J., and Hou, F.J. 2015. Effects of grazing systems on herbage mass and liveweight gain of Tibetan sheep in Eastern Qinghai-Tibetan Plateau, China. Rangeland Journal. 37(2): 181-190. doi: 10.1071/RJ14062.

Tsunoda, M., Newman, C., Buesching, C.D., Macdonald, D.W., and Kaneko, Y. 2018. Badger setts provide thermal refugia, buffering changeable surface weather conditions. Journal of Thermal Biology. 74: 226-233. doi: $10.1016 /$ j.jtherbio.2018.04.005.

Wang, Z.J. 1992. Ecological observation of Marmota himalayana in hibernation period. Endemic Diseases Bulletin. 7(4): 51-55. doi: CNKI:SUN:DFBT.0.1992-04-016.

Wang, Z.H., and Wang, X.M. 2006. Ecological characteristics of Tibetan fox dens in Shiqu county Sichuan province, China. Zoological Research. 27(1): 18-22. doi: 10.3321/j.issn:0254-5853.2006.01.003.

White, T.H., Bowman, J.J.L., Jacobson, H.A., Leopold, B.D. and Smith, W.P. 2001. Forest management and female black bear denning. Journal of Wildlife Management. 65(1): 34-40. doi: 10.2307/3803274.

Xu, D.Q., Xi, J.X., Wang, D.S. and Wang, P.G. 2020. Epidemiological features and countermeasures in Himalayana marmot plague foci in Gannan plateau. Bulletin of Disease Control and Prevention. 35(1): 9-14. doi: 10.13215/j.cnki.jbyfkztb.1912020

Yang, C.T., Zhang, Y., Hou, F.J., Millner, J.P., Wang, Z.F., and Chang, S.H. 2019. Grazing activity increases decomposition of yak dung and litter in an alpine meadow on the Qinghai-Tibet plateau. Plant and Soil. 444: 239-250. doi: 10.1007/s11104-019-04272-x.

Yang, G.R., and Xie, B.Q. 1983. Ecological observation of Marmota himalayana in Northwest Yunnan. Chinese Journal of Zoology. 2: 46-48. doi: CNKI:SUN:BIRD.0.1983-02-017.

Zhang, L., Guo, C., Xiao, Y.H., and Xiang, Z.F. 2019. Den characteristics and their ecological significance for Himalayan marmots (Marmota himalayana ). Acta Theriologica Sinica. 39(03): 34-41. doi: 10. 16829/j. slxb. 150218.

Zhou, Y,P., Wang, P., Ding, S.P., Bai, Z.W., Xue, Q., Han, Y.M. 2015. Relationship between trap-day capture rate and the absolute quantity of Microtus maximowiczii. Forest Pest and Disease. 34(6): 25-27. doi: CNKI:SUN:SLBC.0.2015-06-007.

\section{Hosted file}

Figures.pdf available at https://authorea.com/users/310107/articles/504071-dencharacteristics-and-ecological-significance-of-marmota-himalayana-on-the-qinghai-tibetplateau 